\title{
Nanotechnology and Construction: use of nanoindentation measurements to predict macroscale elastic properties of high strength cementitious composites
}

\section{Nanotecnologia e Construção: emprego do ensaio de nanoindentação na predição das propriedades elásticas de compósitos cimentícios de alta resistência}
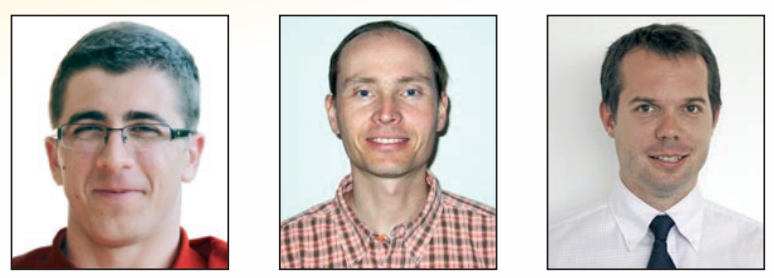

W. R. L. DA SILVA a wilsonecv@gmail.com

J. NĚMEČEK b jiri.nemecek@fsv.cvut.cz

P. ŠTEMBERK ${ }^{\circ}$ stemberk@fsv.cvut.cz

\begin{abstract}
This paper aims to present the experimental results involving the use of nanoindentation measurements and prediction of macroscale elastic properties of high performance cementitious composites (HPCC). The elastic properties of HPCC mixture were evaluated at different length scales by nanoindentation (microscale), and elastic moduli and compressive strength tests (macroscale). The nanoindentation results, obtained by grid indentation with subsequent phase deconvolution, were complemented by an independent porosimetry test and inserted into a two-step analytical homogenization scheme to predict the overall macroscale properties. The final results show that the presented method allows a reliable advanced prediction of HPCC elastic properties indicating, thus, that inserting nanotechnology in the concrete industry can be promising, since it would allow the production of a more predictable composite in an easier and less expensive way.
\end{abstract}

Keywords: nanoindentation, multiscale analysis, high performance cementitious composite.

\section{Resumo}

O presente trabalho visa apresentar os resultados experimentais envolvendo o uso de ensaios de nanoindetação na predição das propriedades elásticas de compósitos cimentícios de alta resistência (CCAR). As propriedades elásticas do CCAR foram avaliadas em diferentes escalas através de ensaios de nanoindetação (microescala), módulo de elasticidade e resistência à compressão (macroescala). Os resultados do ensaio de nanoindetação, obtidos mediante grelha de indentação seguido de decovolução de fase, foram complemetados com os resultados de ensaios independentes de porosimetria e inseridos em um método de homogenização de modo a predizer as propriedades elásticas do compósito avaliado. Os resultados obtidos permitem afirmar que o método utilizado permite uma predição realística das propriedades elásticas dos CCAR. Dessa forma, pode-se afirmar que a inserção da nanotecnologia no setor da construção civil é promissora, uma vez que esta possibilitaria a produção de um produto final mais previsível de um modo mais prático e econômico.

Palavras-chave: nanoindentação, análise multiescalar, compósitos cimentícios de elevada resistência.

\footnotetext{
Wilson Ricardo Leal da Silva (wilsonecv@gmail.com) - Czech Technical University in Prague - MSc. Civil Engineer, PhD student, Department of Concrete and Masonry Structures, Faculty of Civil Engineering, Czech Technical University in Prague (ČVUT).

b Jirï Němeček (jiri.nemecek@fsv.cvut.cz) - Czech Technical University in Prague - Associate Professor, Department of Mechanics, Faculty of Civil Engineering, Czech Technical University in Prague (ČVUT).

Petr Štemberk (stemberk@fsv.cvut.cz) - Czech Technical University in Prague - Associate Professor, Department of Concrete and Masonry Structures, Faculty of Civil Engineering, Czech Technical University in Prague (ČVUT).
} 


\section{Introduction}

Cementitious composites include various types of concretes and mortars and represent the most used building materials. In general, concrete and mortar mixtures are considered by many researches and practitioners as a homogeneous material. Nevertheless, this classification may change according to the level of observation (micro, meso and macroscopic level). Those materials whose homogeneity depends on the observation level are called multiscale materials. Based on this definition, cementitious composites are considered as typical representatives of multiscale materials since they can be treated as homogeneous in the macroscopic level ( $\mathrm{cm} \sim \mathrm{m}$ length scale), and as heterogeneous material in a finer level of observation ( $\mathrm{nm} \sim \mathrm{cm}$ length scale).

Heterogeneity of cementitious composites at the lower level arises from both the chemical reactions from the hydration process, [1,2], and the mechanical mixing of non-reactive components, [3,4]. Moreover, transition zones between the phases and also porosity are present at each scale of the composite.

The multiscale analysis of a composite involves the following steps:

1 microstructure observation (i.e. determination of morphological parameters) and separation of chemically different phases;

2 assessment of mechanical properties of individual phases and their links to chemical properties;

3 upscaling of properties from the microlevel to a broader scale, $[3,5]$. The microstructure observation and determination of phases can be performed, e.g., by analysis of images obtained from optical microscopy, scanning electron microscopy (SEM) or atomic force microscopy (AFM).

Several researches, [4-8], have used these techniques to obtain morphological and chemical parameters of individual material phases with great success, and equally as in this paper, the microstructure analysis has often been supplemented by porosity measurements obtained by mercury intrusion porosimetry and/or image analysis, among other methods.

The micromechanical analysis of individual material phases ( $\mathrm{nm} \sim \mathrm{mm}$ scale) can be obtained by the nanoindentation technique. This corresponds to a unique technique which allows the mechanical properties of small volumes at nano and micro level. The principle of nanoindentation lies in forcing a very small diamond tip to the material surface while the changes in the applied load and the penetration depth are measured simultaneously, [9]. By using this method, material properties, such as elastic modulus, hardness, plastic or viscous parameters, can be obtained from experimental readings for a given material volume, [9-11].

The macrolevel analysis is performed by different types of standardized macroscopic tests (e.g., by the static compression, tension or bending and/or by dynamic tests) where the overall material properties are obtained on large specimens ( $\mathrm{cm} \sim \mathrm{m}$ scale).

Transition between the micro and macro levels can be treated with a micromechanical approach that separates the levels by defining a characteristic scale and related representative volume elements (RVE) for each of the levels, [12]. The response of the micromechanically heterogeneous RVE can be averaged through different homogenization techniques, [12-14]. A significant group of analytical methods is based on the classical Eshelby's solution of ellipsoidal inclusions embedded in a matrix, [13], namely the Mori-Tanaka method, the selfconsistent scheme and others, [12]. Numerical homogenizations can



include finite element computations or fast Fourier transformation, [1416]. Among the analytical homogenization schemes, the Mori-Tanaka method, which performance was justified by some researchers when used for cementitious composites, [3,5,17], is frequently used for its simplicity and wide applicability in terms of the concentration range of the multiple phases involved in the analysis.

High performance Cementitious Composite, HPCC, are those cementitious-based composites, e.g., mortar and concrete, which meet special performance and comply with uniformity requirements that cannot be always achieved by conventional materials and practices, [18]. By defining the link between microstructure, micromechanical properties and macroscopic mechanical performance of such composite, one can optimize its mechanical properties in an easier and experimental less expensive way. This possibility is highly inviting for the concrete industry, since they would be able to deliver a more predictable product, for example, a high performance concrete with the desired elastic properties.

In this paper, a combination of nanoindentation technique and approaches mentioned along these lines has been applied in order to determine macroscale elastic properties of the high performance cementitious composites.

\section{Experimental program and evaluation of results}

This section highlights the details on the tested materials, mixture compositions, sample preparation, mixing procedure and tests performed. The experimental setup for the analysis of mechanical properties at different levels is also presented.

\subsection{Materials}

The tests were carried out with mortar mixtures further denoted as $\mathrm{C} 1$. The mortar mixtures contained cement CEM II/A-S $52.5 \mathrm{~N}$ (Table 1), high-range water reducing admixture Stachement 2000 , and quartz 


\section{Table 2 - Grain size distribution of aggregates (in wt.\%)}

\begin{tabular}{|ccc|}
\hline & ST 01/06 & ST 06/12 \\
Middle grain size $\left(\mathrm{d}_{50}\right)(\mathrm{mm})$ & 0.38 & 0.88 \\
AFS grain fineness number & 30 & 14 \\
Bulk density $\left(\mathrm{kg} / \mathrm{m}^{3}\right)$ & 1500 & 1600 \\
Grain size $(\mu \mathrm{m})$ & ST 01/06 & ST 06/12 \\
$>4000$ & - & - \\
$>1250$ & - & $7.0 \%$ \\
$>1000$ & $0.0 \%$ & - \\
$>800$ & - & - \\
$>630$ & $12.0 \%$ & $91 \%$ \\
$>315$ & - & - \\
$>200$ & $85.0 \%$ & - \\
$>100$ & $2.0 \%$ & - \\
$<100$ & $1.0 \%$ & $2.0 \%$ \\
\hline
\end{tabular}

filler, provided by Sklopísek Střeleč, CZ, with the maximum grain size of $0.063 \mathrm{~mm}$. A mix of two fine quartz sands, ST06/12 and ST01/06, also provided by Sklopísek Střeleč, CZ, were used as aggregates These are mainly composed by $\mathrm{SiO}_{2}(99.2 \%)$ and $\mathrm{Fe}_{2} \mathrm{O}_{3}(0.04 \%)$. The sand mix included 50 vol.\% of ST06/12 (with the grain size range varying from $0.63 \mathrm{~mm}$ to $1.25 \mathrm{~mm}$ ) and 50 vol.\% of ST01/06 (with the grain size range varying from $0.10 \mathrm{~mm}$ to $0.63 \mathrm{~mm}$ ). The grain size distribution of both the aggregates is presented in Table 2 .

\subsection{Mixture compositions and mixing procedure.}

The compositions of mortar mixture in mass and volume is presented in Table 3. This composition was defined on previous study results, [21], and adjusted in order to obtain higher compressive strength and spread diameter of $\sim 180 \mathrm{~mm}$ in the flow-table test. The mixing procedure is described in Table 4. After mixed and tested in the fresh state, nine samples were molded for the tests in the hardened state, whose details are described in the following sections.

\subsection{Macroscale analysis}

\subsubsection{Macroscopic elastic modulus and strength}

For the evaluation of elastic modulus and compressive strength six prismatic specimens $40 \times 40 \times 160 \mathrm{~mm}^{3}$ were molded. The molding was performed in two layers of $2.0 \mathrm{~cm}$, each one compacted under a cycle of 15 seconds under vibration on a vibration table. The samples were then sealed with plastic foil and kept in the mold for 24 hours. Later, the specimens were demolded and stored in water for 20 days until the tests in the hardened state were performed. Before testing, the top and bottom ends of the specimens were polished to obtain flat parallel surfaces.

The uniaxial compression tests were performed by using an electromechanical universal test machine (Testatron, Otto Wolpert-Werke $\mathrm{Gmbh}$ ). The load was measured by a beam load cell (MTS $100 \mathrm{kN}$ ) attached to the electromechanical actuator. Two axial extensometers with the gauge length of $50 \mathrm{~mm}$ were used to measure the displacement of the specimen. The extensometers were located on the lateral surfaces of the samples as indicated in Figure 1a. The centric loading was checked at the beginning of the test and in case of any bending occurrence, the test was stopped and the specimen adjusted to its center position. The complete experimental set up is presented in Figure $1 \mathrm{~b}, \mathrm{c}$. Four loading cycles were performed on each sample to exclude the initial inelasticity (Figure 2a). The elastic modulus was computed from the linear part of the last cycle in the stress-strain curve, see Figure $1 \mathrm{~b}$. The loading continued until the ultimate load was reached in order to obtain the compressive strength of each sample.

\subsection{Microscale analysis}

\subsubsection{Nanoindentation tests}

A cylindrical sample of $30 \mathrm{~mm}$ in diameter was prepared for nanoindentation testing (Figure 3). The molding and curing proce-

Table 3 - Material density and mortar mixture composition, in mass and volume

\begin{tabular}{|cccc|} 
Material & $\begin{array}{c}\text { Density } \\
\left(\mathrm{kg} / \mathrm{m}^{3}\right)\end{array}$ & $\begin{array}{c}\text { Composition in } \\
\text { mass }\left(\mathrm{kg} / \mathrm{m}^{3}\right)\end{array}$ & $\begin{array}{c}\mathrm{Cl} \\
\text { Composition in } \\
\text { volume }\left(\mathrm{dm}^{3} / \mathrm{m}^{3}\right)\end{array}$ \\
\hline Cement & 3000 & 596.2 & 198.7 \\
Quartz filler & 2650 & 223.6 & 84.4 \\
ST01/06 & 2650 & 633.4 & 239.0 \\
ST06/12 & 2650 & 633.4 & 239.0 \\
Admixture & 1020 & 3.4 & 3.3 \\
Water & 1000 & 238.8 & 238.8 \\
\hline
\end{tabular}




\begin{tabular}{|ccc|}
\hline Table 4 - Mixing procedure & \\
\hline Procedure & & \\
\hline Dry materials mixed together & $\rightarrow$ & Time (s) \\
\hline Addition of water & $\rightarrow$ & 30 \\
Mixture of materials and water & $\rightarrow$ & 60 \\
Edge shovel clean & $\rightarrow$ & 30 \\
Addition of superplasticizer & $\rightarrow$ & 30 \\
Mixture of the base mortar & $\rightarrow$ & 90 \\
\hline
\end{tabular}

dure was held the same as described in section 2.3.1. The specimen was cut out from the middle section of a larger volume by using a precision diamond saw. Then, dried surfaces were grinded by SiC papers (grit \#2000 and \#4000) and polished by cloth with $0.25 \mathrm{~mm}$ diamond spray. Finally, the surfaces were cleaned by washing in alcohol and ultrasonic bathing. The resulting surface roughness (root-mean-square) was checked with AFM to be less than $20 \mathrm{~nm}$ on $5 \times 5 \mu \mathrm{m}$ area.

The nanoindentation measurements were carried out in the CSM Nanohardness tester ${ }^{\circledR}$ machine. The three-sided pyramidal indenter tip (Berkovich) was used to perform a massive grid of $16 \times 18$ (288) indents with the mutual distance of indents of $8 \mu \mathrm{m}$ as illustrated in Figure 4a. The indentation location was selected carefully by a high magnification optical microscope prior to testing to ensure that they lie away from large aggregate. The microstructure at the selected location consisted of all the cementitious matrix phases in

\section{Figure 1 - Elastic modulus tests: (a) specimen dimensions and $(b, c)$ experimental setup}



A



B



C

Figure 2 - Elastic modulus: (a) elastic loading cycles and (b) example of compressive stress-strain curve in elastic regime



A

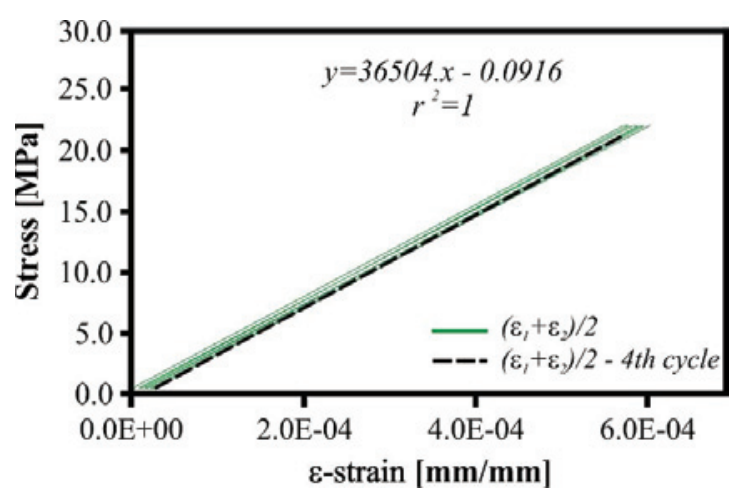

B 
Figure 3 - Specimens for nanoindentation test: initial and final configuration

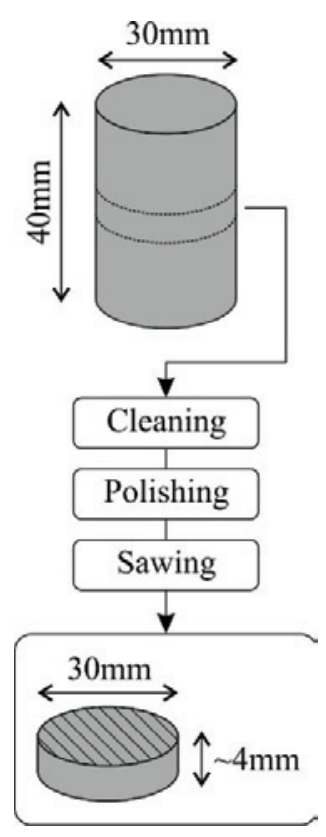

a sufficient content. Thus, it could be considered as a representative volume element (RVE) on the matrix level (level I) having the dimension $\sim 100 \mathrm{~mm}$. Individual indent size (depth of penetration h) was chosen to be $\mathrm{h} \approx 200 \mathrm{~nm}$, [19], so that the affected volume under the indenter, which can be estimated as $3 \times$ h (i.e. $\sim 600 \mathrm{~nm}$ ), was smaller than the characteristic sizes of inclusions to avoid significant phase interactions. However, in the dense matrix of a HPCC full exclusion of interactions can hardly be achieved since it presents several phases of different stiffness. Due to surface roughness, which cannot be further decreased by mechanical way,
[23], the indent size must be kept in hundreds of $\mathrm{nm}$. The indent size 100 300 nm also suits well the concept of grid indentation on cement pastes, [19]. It can be assumed that hard quartz filler, with maximum $\sim 60 \mathrm{~mm}$ size, in larger volumes can also cause stiffening of less stiff phases like C-S-H gels during indentation. The error incorporated into the measurements can be roughly quantified by FEM computation as 13 25\%, [24]. Similar errors are incorporated into measurement of stiff inclusions surrounded by a compliant matrix, however their content is smaller and thus their influence also decreases. It can be assumed that such errors are naturally included in nanoindentation measurements and should be considered in the final comparisons.

The nanoindentation loading regime contained loading at $12 \mathrm{mN} /$ $\mathrm{min}$, holding for 10 seconds and unloading at $12 \mathrm{mN} / \mathrm{min}$ as shown in Figure $4 \mathrm{~b}$. The holding period of 10 seconds with constant force was added mainly to minimize creep effects on the elastic unloading, [25].

The elastic modulus of the analyzed phase was determined according to the Oliver-Pharr methodology, [10]. The analysis is based on Eq.(1) to define the indentation (reduced) modulus:

$$
E_{r}=\frac{1}{2 \beta} \frac{\sqrt{\pi}}{\sqrt{A}} S
$$

$$
S=\left.\frac{d_{P}}{d_{h}}\right|_{h=h \max }
$$

where $\mathrm{S}$, which is defined by Eq.2, is the contact stiffness assessed as a slope of the unloading branch at the maximum depth $\mathrm{h}_{\max }$ and the peak load, $A_{c}$ is the projected contact area at the peak load, and $\beta$ is the geometrical correction factor introduced to correct the non-

\section{Figure 4 - Nanoindentation tests: (a) Indentation grid, and (b) loading and penetration depth diagram}



A

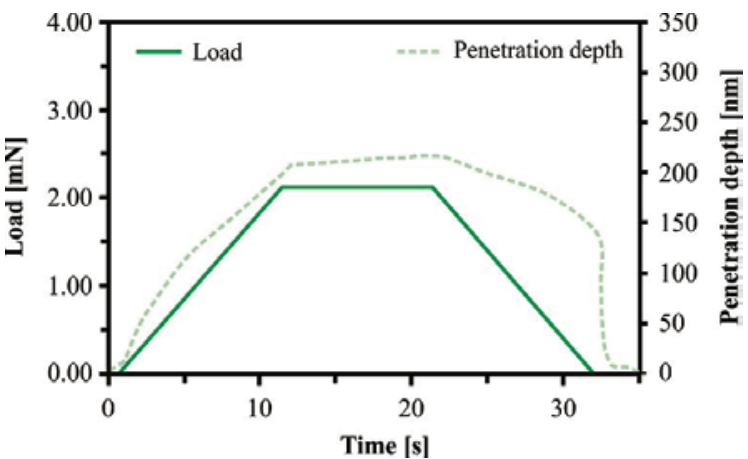

B 
symmetrical indenter shape ( $\beta=1.034$ for Berkovich tip). The effect of non-rigid indenter can be taken into consideration by the equality of compliances shown in Eq.(3),

$\frac{1}{E_{r}}=\frac{1-v^{2}}{E}+\frac{1-v_{i}^{2}}{E_{i}}$

where $\mathrm{E}$ corresponds to the elastic modulus and $\mathrm{n}$ the Poisson's ratio of the tested materials, while $E_{i}$ and $v_{i}$ are the parameters of the indenter $\left(E_{i}=1141 \mathrm{GPa}\right.$ and $v_{i}=0.07$ for a diamond).

\subsubsection{Deconvolution procedure}

The individual phase properties of the analyzed mixtures were determined by applying the statistical deconvolution to elastic modulus histograms, $[19,4]$. The results on the elastic moduli in the form of frequency plots are analyzed so that the minimization procedure seeks parameters of $n$ Gauss distributions in an experimental probability density function, PDF.

In the deconvolution algorithm, a random seed and minimizing criteria based on quadratic deviations between the experimental and theoretically computed overall PDFs are calculated to find the best fit. A comprehensive review about the deconvolution procedure is described in [4]. The number of the searched phases was fixed to four based on the number of characteristic peaks in the PDF. The dominant phases in the PDF need not necessarily to correlate with the chemically distinct phases and are further considered as mechanically distinct phases which will be used in the homogenization procedure.

\subsection{Analytical elastic homogenization}

The homogenization corresponds to a technique used to upscale the mechanical properties from the microscale to the upper level to find the effective properties of the RVE. In this paper, the elastic homogenization was performed by means of the analytical Mori-Tanaka scheme, [20]. This scheme describes a composite by a morphologically prevailing matrix (the reference medium) reinforced by distinct non-continuous spherical inclusions. In the Mori-Tanaka method, the homogenized bulk and shear moduli of a $r$-phase composite are assessed as indicated in Eq.4 to 7.

$k_{\mathrm{hom}}=\frac{\sum_{r} f_{r} \cdot k_{r}\left(1+\alpha_{0} \cdot\left(k_{r} / k_{0}-1\right)\right)^{-1}}{\sum_{r} f_{r}\left(1+\alpha_{0} \cdot\left(k_{r} / k_{0}-1\right)\right)^{-1}}$

$$
\mu_{\mathrm{hom}}=\frac{\sum_{r} f_{r} \cdot \mu_{r}\left(1+\beta_{0} \cdot\left(\mu_{r} / \mu_{0}-1\right)\right)^{-1}}{\sum_{r} f_{r}\left(1+\beta_{0} \cdot\left(\mu_{r} / \mu_{0}-1\right)\right)^{-1}}
$$

$$
\alpha_{0}=\frac{3 \cdot k_{0}}{3 \cdot k_{0}+4 \cdot \mu_{0}}
$$

$$
\beta_{0}=\frac{6 \cdot k_{0}+12 \cdot \mu_{0}}{15 \cdot k_{0}+20 \cdot \mu_{0}}
$$

where the subscript 0 corresponds to the reference medium and $r$ corresponds to a particular inclusion. Thus, $k_{0}$ and $\mu_{0}$ are the bulk and shear moduli of the reference medium, while $k_{r}$ and $\mu_{r}$ refer to the inclusion phases. These values are the input to the equations that define the homogenized elastic modulus. After defining these values, the bulk and shear moduli can be recomputed to the elastic modulus and the Poisson's ratio though Eq.8 and 9.

$E_{\mathrm{hom}}=\frac{9 \cdot k_{\mathrm{hom}} \cdot \mu_{\mathrm{hom}}}{3 \cdot k_{\mathrm{hom}}+\mu_{\mathrm{hom}}}$
$v_{\mathrm{hom}}=\frac{3 \cdot k_{\mathrm{hom}}-2 \cdot \mu_{\mathrm{hom}}}{6 \cdot k_{\mathrm{hom}}+2 \cdot \mu_{\mathrm{hom}}}$

\section{Results}

\subsection{Experimental results in hardened state - Macroscale analysis}

\subsubsection{Elastic modulus and Compressive strength}

The results from elastic modulus and uniaxial compression tests are summarized in Table 5.

\begin{tabular}{|ccc|}
\hline $\begin{array}{c}\text { Table } 5 \text { - Elastic modulus and Compressive } \\
\text { strength - Macroscale analysis }\end{array}$ \\
Sample & $\begin{array}{c}\text { Elastic } \\
\text { modulus (GPa) }\end{array}$ & $\begin{array}{c}\text { Compressive } \\
\text { strength } \\
\text { (MPa) }\end{array}$ \\
\hline 1 & 41.2 & 61.4 \\
2 & 38.1 & 58.2 \\
3 & 37.5 & 49.4 \\
4 & 39.1 & 57.0 \\
5 & 38.8 & 55.7 \\
6 & 39.5 & 54.7 \\
$\begin{array}{c}\text { Average } \\
\text { result (GPa) }\end{array}$ & 39.0 & - \\
$\begin{array}{c}\text { Standard } \\
\text { deviation (GPa) }\end{array}$ & 1.28 & - \\
\hline
\end{tabular}


Figure 5 - Example of load-penetration curves



\subsection{Experimental results in hardened state - Microscale analysis}

\subsubsection{Nanoindentation}

A total of 288 indents to the cementitious matrix were performed. Examples of the load-penetration curves and related load/penetration-time diagrams showing indents to differently stiff phases are presented in Figure 5 and 6, respectively.

All relevant indents were analyzed by the Oliver-Pharr method, [10], for an elastic modulus with the assumption of constant Poisson's ratio 0.2 for all indents, since the influence of the selected Poisson's ratio in the relevant range $0.18-0.22$ on the evaluation is very small, [17]. Subsequently, the frequency plots, with bin size set to $1.0 \mathrm{GPa}$, and related experimental probability density

Figure 6 - Load and depth of penetration versus time

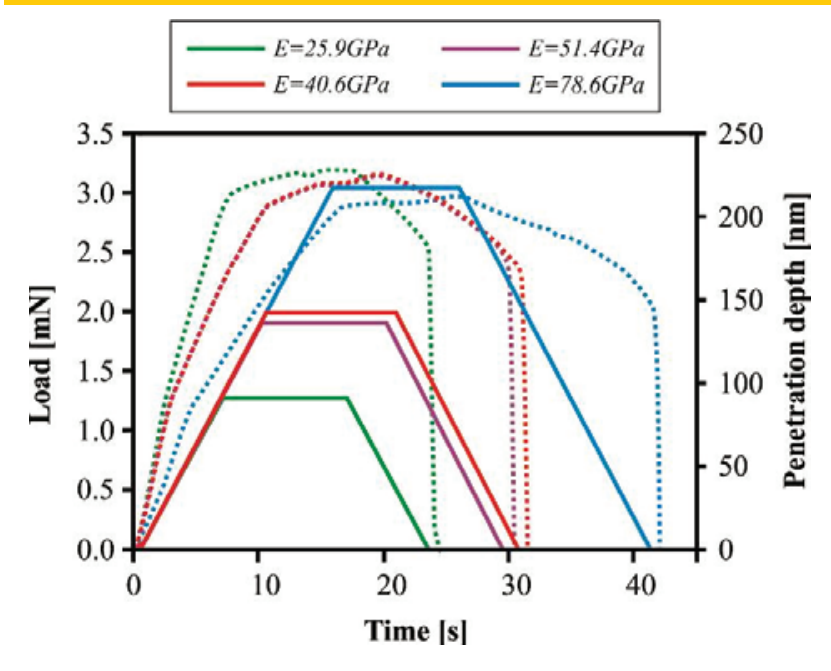

Figure 7 - Experimental and best-estimated PDF obtained by deconvolution

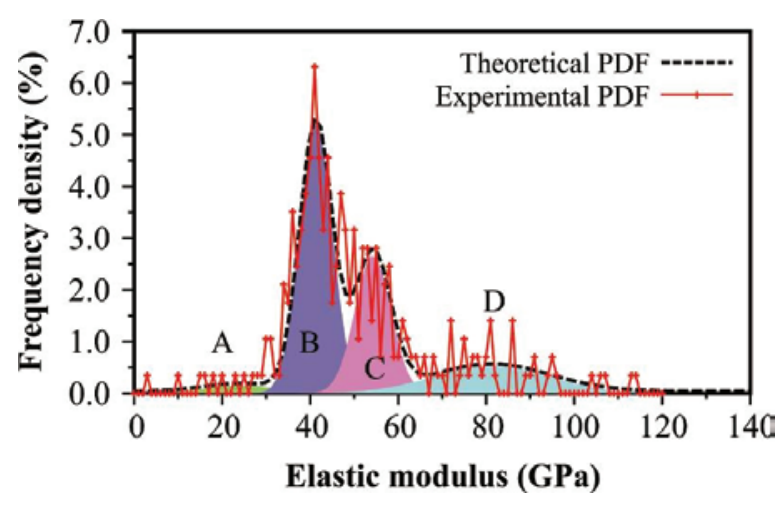

functions (PDFs) were computed. The deconvolution method was applied to PDFs as illustrated in Figure 7. The obtained results are listed in Table 6.

As mentioned above, the results are considered as results received on mechanically distinct phases and there is no intention to link them with pure chemical phases, such as C-S-H gels with different densities, Portlandite, interfacial zones, etc., $[5,17,19]$. Despite the fact that the results from deconvolution present mechanically distinct phases rather than chemically distinct phases, they are closely related. Based on the SEM imaging, cement chemistry and mixture composition, it is assumed that the phase A in Figure 7 is composed of low stiffness porous phases, the phase $\mathrm{B}$ contains majority of the main hydration products (C-S$\mathrm{H}$ gels and partly $\mathrm{Ca}(\mathrm{OH})_{2}$ ), the phase $\mathrm{C}$ is composed of high stiffness hydration products (high stiffness $\mathrm{C}-\mathrm{S}-\mathrm{H}$ and partly $\mathrm{Ca}(\mathrm{OH})_{2}$ ), the phase $\mathrm{D}$ contains the remaining non-hydrated clinker, fly ash or quartz filler. Due to unavoidable phase interactions, the obtained elastic moduli do not exactly represent material constants for pure phases, which is manifested mainly for the stiffest components, such as the clinker, whose elastic modulus reaches 130 GPa on a pure clinker sample, [25,29]. However, separation of the mechanical performance of the individual components is not possible from the measured response and the influence of

Table 6 - Elastic modulus and volume fraction obtained by deconvolution

\begin{tabular}{cccc|}
$\begin{array}{c}\text { Matrix } \\
\text { phases }\end{array}$ & $\begin{array}{c}\text { Elastic } \\
\text { modulus } \\
(\mathrm{GPa})\end{array}$ & $\begin{array}{c}\text { S.d. } \\
(\mathrm{GPa})\end{array}$ & $\begin{array}{c}\text { Volume } \\
\text { fraction } \\
(\%)\end{array}$ \\
\hline A & 24.4 & 8.35 & 6.3 \\
B & 41.3 & 3.70 & 48.8 \\
C & 54.3 & 4.07 & 27.4 \\
D & 81.2 & 13.29 & 17.5 \\
\hline
\end{tabular}




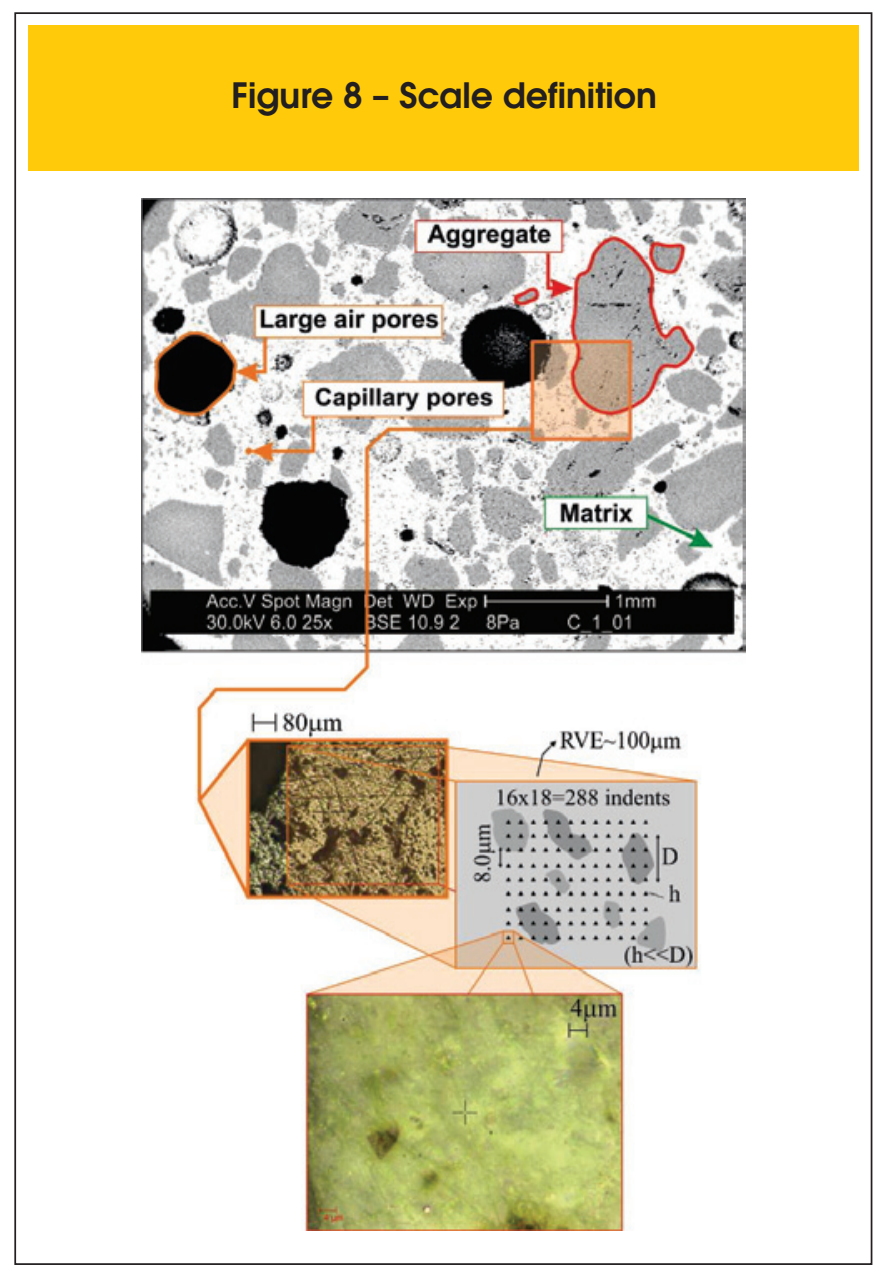

interactions can be just estimated as discussed in section 2.4.1. Further, the evaluated micromechanical values are considered as the first estimates and as such they neglect the interaction phenomena in the following upscaling.

\subsubsection{Homogenization}

The microstructure of the analyzed composites was split into two levels. The first level, which corresponds to the matrix level, named as level I, is characterized by all the matrix phases having characteristic dimensions less than $d \approx 10 \mathrm{~mm}$ (i.e. hydration products, clinker, quartz filler, fly ash). The RVE size which also corresponds to the indentation grid has the dimension $\sim 100 \mathrm{~mm}$. Therefore, the scale separability condition $[12,19]$ $h<<d<<L$, where $h$ is the indent size, $d$ is the characteristic inclusion size and $L$ is the RVE size, holds. The situation is illustrated in Figure 8.

Since the volume affected by the indentation is $\sim 0.6 \mathrm{~mm}^{3}$ it is assumed that all the pores smaller than this limit are included in the indentation results. It includes mainly nanoporosity. However, a small part of pores with the dimension of $0.6 \sim 10 \mathrm{~mm}$, which corresponds to approximately $1 / 10$ of RVE size, also lies in the level I but cannot be detected by the nanoindenter. Consequently, this porosity was included as an additional mechanical phase in the level I (Table 7).

Mercury intrusion porosimetry (MIP) performed on the crushed pieces of the composites of the size of up to $5 \mathrm{~mm}$ was used for assessment of the level I porosity, i.e., pores in the range from $0.6 \mu \mathrm{m}$ to $10 \mu \mathrm{m}$, which equaled to $2.4 \mathrm{vol} . \%$, see Figure 9 . The results for the homogenized elastic modulus and the Poisson's ratio obtained by the Mori-Tanaka method for level I are presented in Table 7. Subsequently, the level of the whole mortar, named as level II, was constructed. It consisted of the homogenized phase of the level I (matrix) and the rest of components, i.e. large sand particles, aggregate and air voids, which corresponds to capillary pores with diameter greater than $10 \mu \mathrm{m}$ and large air voids coming from entrapped air greater than $1 \mathrm{~mm}$. Since the aggregate does not change chemically in the composite, its portion is given by the initial mixture proportions, defined in Table 3. The elastic modulus and the Poisson's ratio of the quartz aggregates were assumed as $71.8 \mathrm{GPa}$ and 0.17 , respectively, [30]. Sometimes, an additional phase, an interfacial zone between the matrix and the aggregate, is considered as a separate phase in multiscale models. For the herein presented analysis, the properties of possible ITZ are naturally included in the nanoindentation data since the indentation grid was squeezed between the large aggregate. Moreover, the very dense matrix itself consists of possibly interconnecting ITZs surrounding the pure phases.

Due to the large span of the pore diameters ranging from $\mathrm{mm}$ to $\mathrm{mm}$, a combination of imaging techniques was used to assess

\section{Table 7 - Mechanical properties of the level I obtained by homogenization}

\begin{tabular}{|c|c|c|c|c|c|c|}
\hline Phase & $\begin{array}{l}\text { Elastic } \\
\text { modulus } \\
\text { (GPa) }\end{array}$ & $v$ & $\begin{array}{l}\text { Volume } \\
\text { fraction } \\
(\%)\end{array}$ & $\begin{array}{l}\text { Corrected } \\
\text { volume } \\
\text { fraction (\%) }\end{array}$ & $\begin{array}{l}\text { Mori- } \\
\mathrm{E}_{\text {hom }}^{\text {level-1 }} \\
\text { (GPa) }\end{array}$ & $\begin{array}{l}\text { naka } \\
v_{\text {hom }}^{\text {level-1 }}\end{array}$ \\
\hline$A$ & 24.4 & 0.20 & 6.3 & 6.2 & \multirow{5}{*}{45.9} & \multirow{5}{*}{0.20} \\
\hline B & 41.3 & 0.20 & 48.8 & 47.6 & & \\
\hline C & 54.3 & 0.20 & 27.4 & 26.7 & & \\
\hline $\mathrm{D}$ & 81.2 & 0.20 & 17.5 & 17.1 & & \\
\hline Porosity & - & - & - & 2.4 & & \\
\hline
\end{tabular}




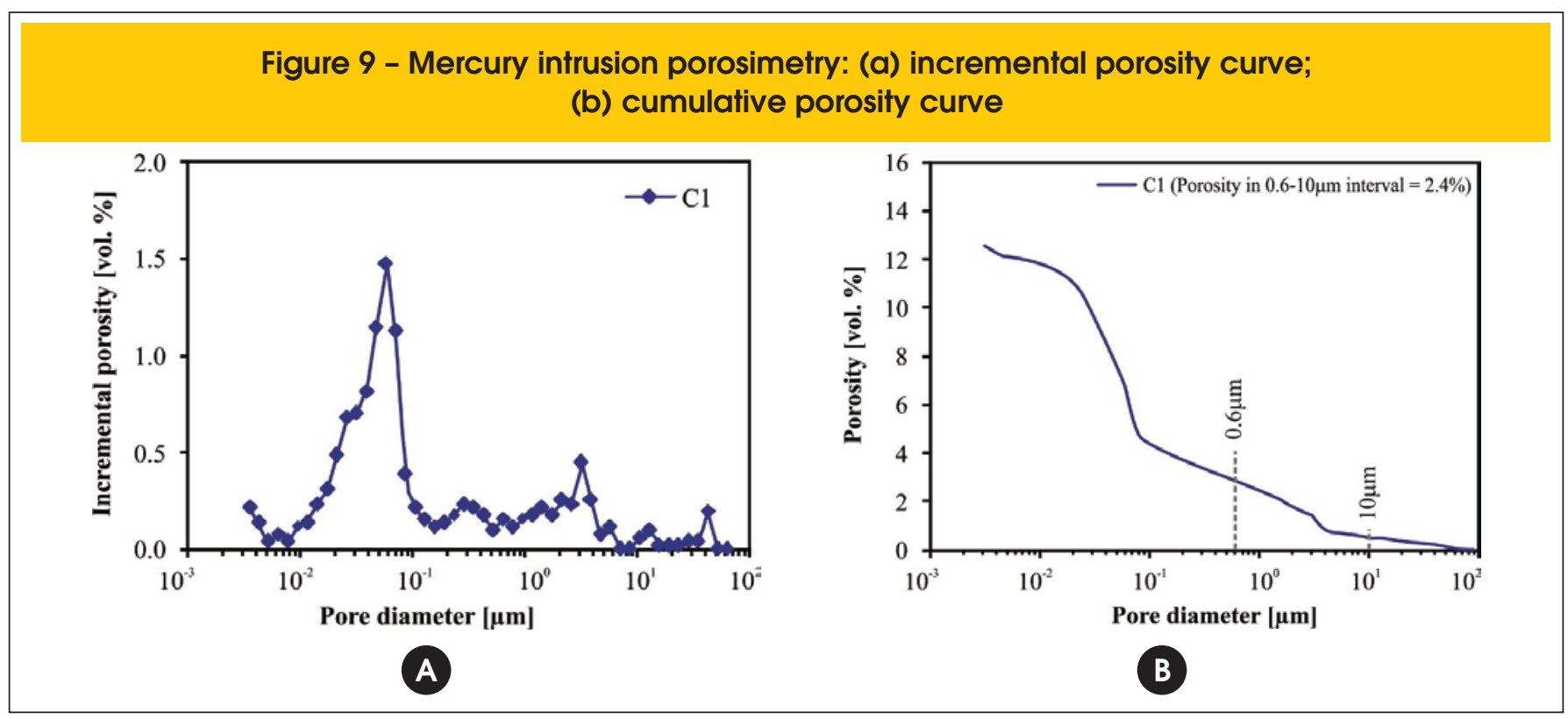

\begin{tabular}{|c|c|c|c|c|c|}
\hline \multicolumn{6}{|c|}{ Table 8 - Mechanical properties of level II obtained by homogenization } \\
\hline Phase & $\begin{array}{c}\text { Elastic } \\
\text { modulus ( } \mathrm{GPa} \text { ) }\end{array}$ & $v$ & $\begin{array}{l}\text { Volume } \\
\text { fraction (\%) }\end{array}$ & $\begin{array}{l}\text { E } \begin{array}{l}\text { level-II } \\
\text { hem } \\
(G P a)\end{array}\end{array}$ & $\begin{array}{l}v_{\text {hom }}^{\text {levell }} \\
(G P a)\end{array}$ \\
\hline Level I - homogenized matrix & 45.9 & 0.20 & 47.6 & \multirow{4}{*}{46.2} & \multirow{4}{*}{0.18} \\
\hline Aggregate (0.10-1.25mm) & 71.8 & 0.17 & 43.2 & & \\
\hline $\begin{array}{c}\text { Capillary pores }>10 \mu \mathrm{m}-1 \mathrm{~mm} \\
\text { (BSE) }\end{array}$ & - & - & 8.92 & & \\
\hline Large air pores $>1 \mathrm{~mm}(\mathrm{OI})$ & - & - & 0.31 & & \\
\hline
\end{tabular}

the level II porosity. Image analysis was employed on segmented back-scattered (BSE) electron and optical images (OI). The segmentation was performed on the thresholded binary images as illustrated in Figure 9.

The medium size porosity $(10 \mu \mathrm{m}$ to $1 \mathrm{~mm})$ was assessed from 25× magnification BSE images, see Figure 10. Fifteen different BSE images were analyzed and the results averaged. The analysis yielded $8.92 \%$ (Table 8 ). The pores larger than $1 \mathrm{~mm}$ (mainly entrapped air pores) were assessed similarly also from $\mathrm{Ol}$ with 10x magnification, see Figure 11. As indicated in Table 8 , the analysis resulted with $0.31 \%$ of porosity. The results obtained for the homogenized elastic modulus and the Poisson's ratio by using the MoriTanaka method are shown in Table 8 for the level II.

\section{Verification of the results}

The verification of the results is based on the comparison of the elastic modulus obtained from the level II homogenization (Table 8) and the macroscopic tests (Table 5). These results are summarized in Table 9. The relative error between the results obtained from the macroscale elastic modulus tests and homogenized values is within the order of tens of percent.

As mentioned in section 2.4.1, evaluation of nanoindentation tests is not error-free. In the case of HPCC, which consists in a dense matrix, in which several phases of different stiffness occur, the interaction between the matrix and these different phases can affect the nanoindentation results. Therefore, it can be assumed that the error presented in Table 9 is caused 
by the phase interactions influencing the nanoindentation results. The influence of the evaluation by deconvolution is also considered. This observation is supported by the fact that the level II homogenization is based on mixture proportions and independent image analysis results. Therefore, the observed overall error must come from the basic indentation data used in the level I homogenization. In order to decrease the effect of interactions and thus refine the computations, it would be necessary to decrease the size of indents. Nonetheless, such refinement is hardly achievable with standard polishing techniques that provide surface roughness at least in the order of several tens of nanometers on the given sample composition. In spite of the error, the use of nanoindentation tests cannot not be either discarded or substituted since it corresponds to the best experimental technique which allows direct assessing of the mechanical properties of material volumes with dimensions on the nanometer scale, [3], reason why this technique has been chosen in the presented research.

\section{Conclusions}

In this paper, nanoindentation measurements have been applied

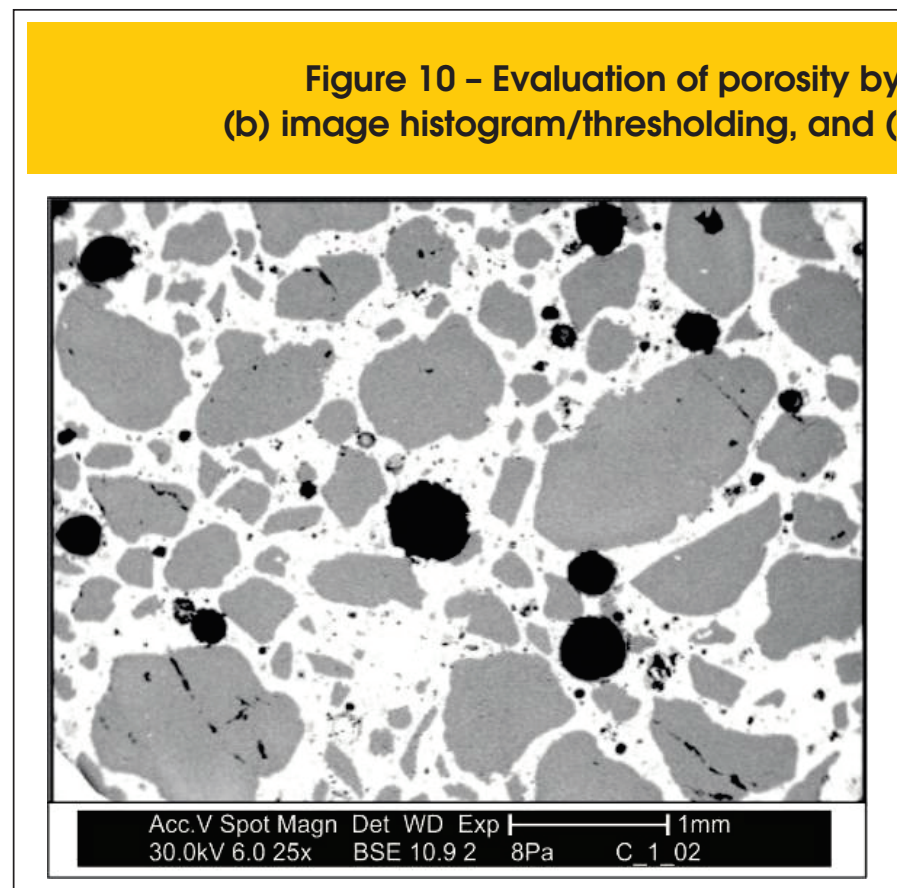

A

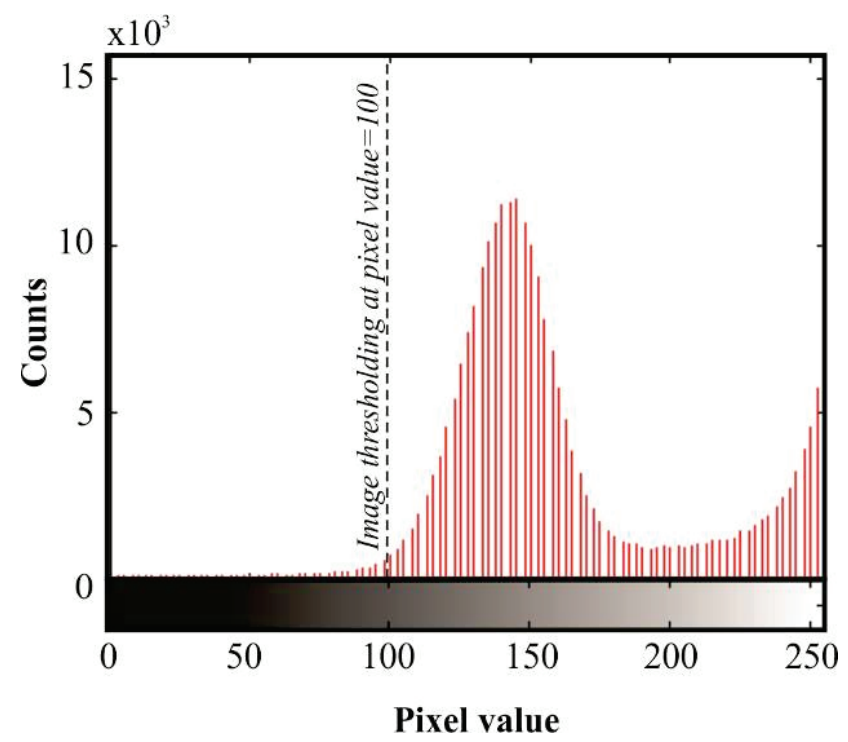

B

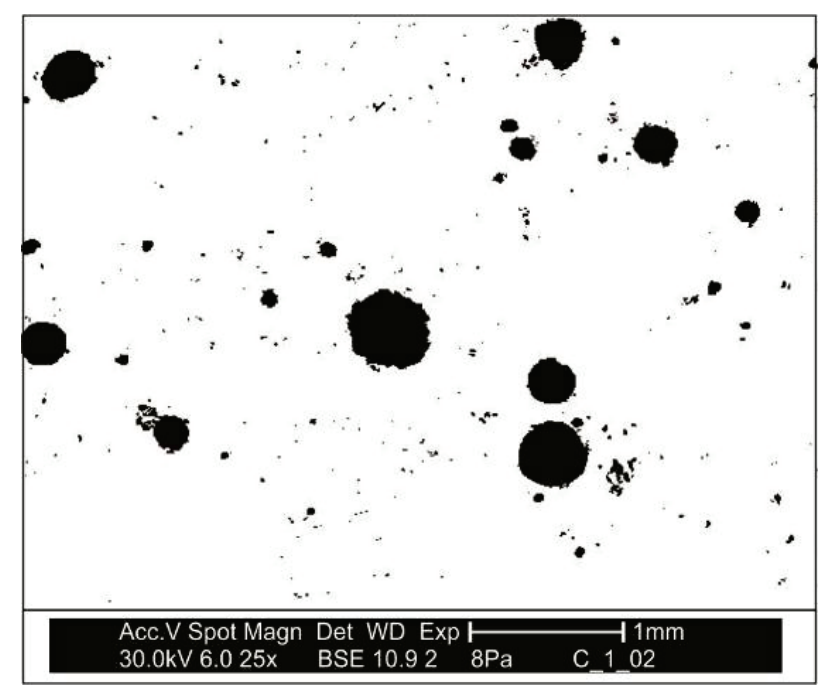

C 
for determination of macroscale elastic properties of HPCC based on multiscale analysis. Based on the obtained results the following conclusions can be drawn.

The experimental results showed that the use of statistical grid nanoindentation, which was applied for the mechanical analysis on the microscale level, can be performed in a very effective and inexpensive way on the matrix components and provides reliable estimates of their stiffness.

It has been also proved that the use of several independent experimental techniques and their combination in the homogenization procedures, offers a cost effective tool for virtual testing of macroscale mechanical performance of HPCC, which is composed by a mix of different chemical and mechanical phases. This feature can be highly attractive to the concrete industry, since the use of described method would dramatically reduced the total volume of experimental work and, more important, it would enable the production of a more predictable composite, in the present case, a more predictable high performance concrete.

\section{Acknowledgements}

The support of the Czech Science Foundation (project 103/09/1748), Grant Agency of the Czech Technical University in Prague (grants No. SGS12/116/OHK1/2T/11 and SGS11/107/

Figure 11 - Evaluation of porosity by optical image analysis: (a) original image, (b) corrected image, (c) image histograms and (d) final processed image (pores are in black)

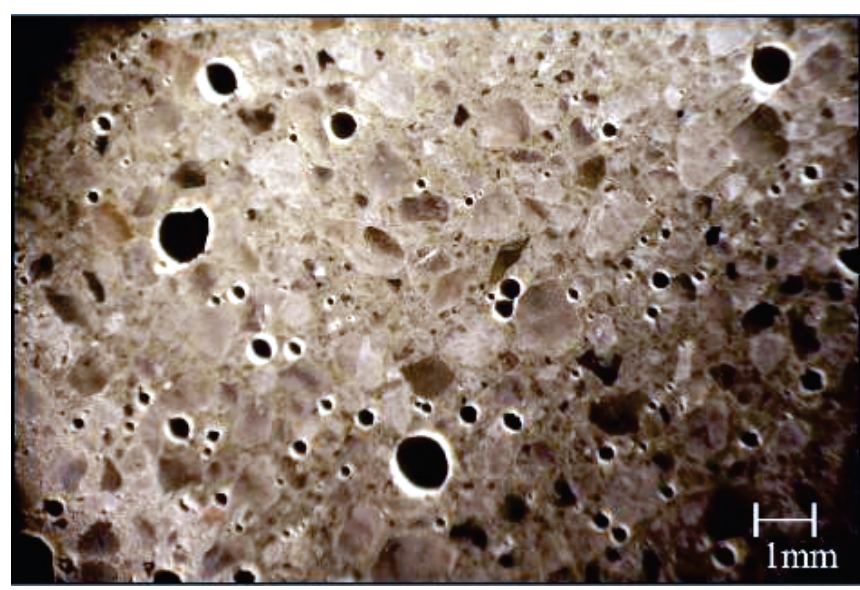

A

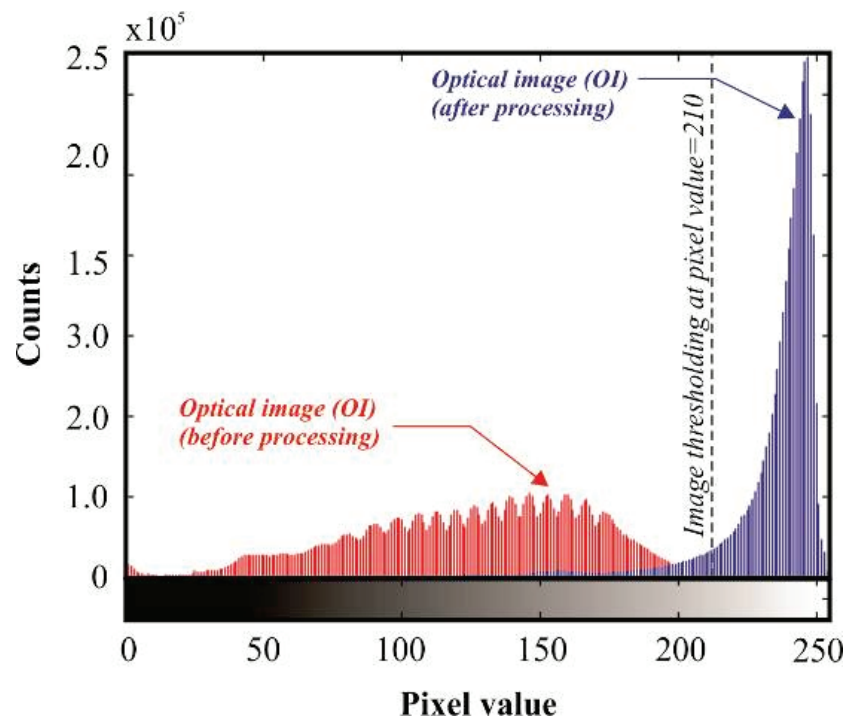

C

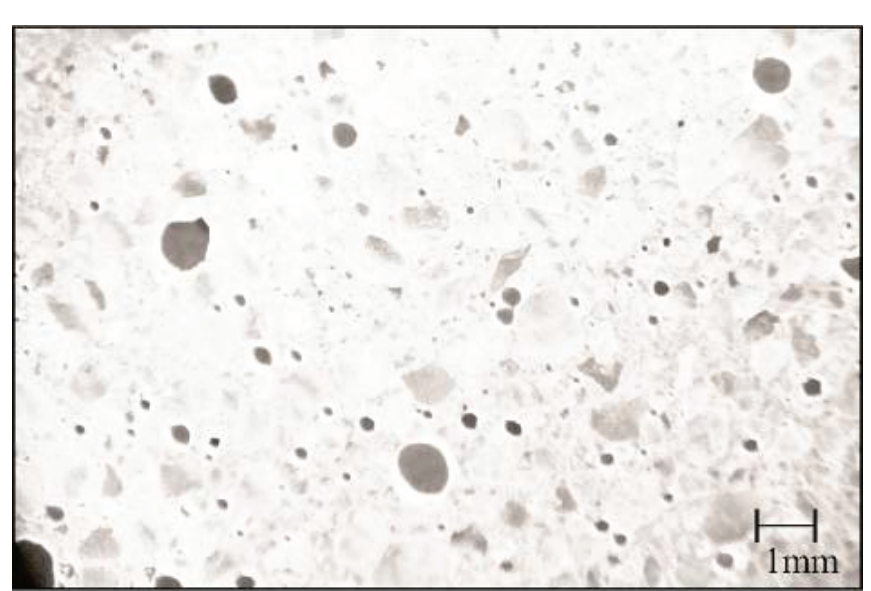

B

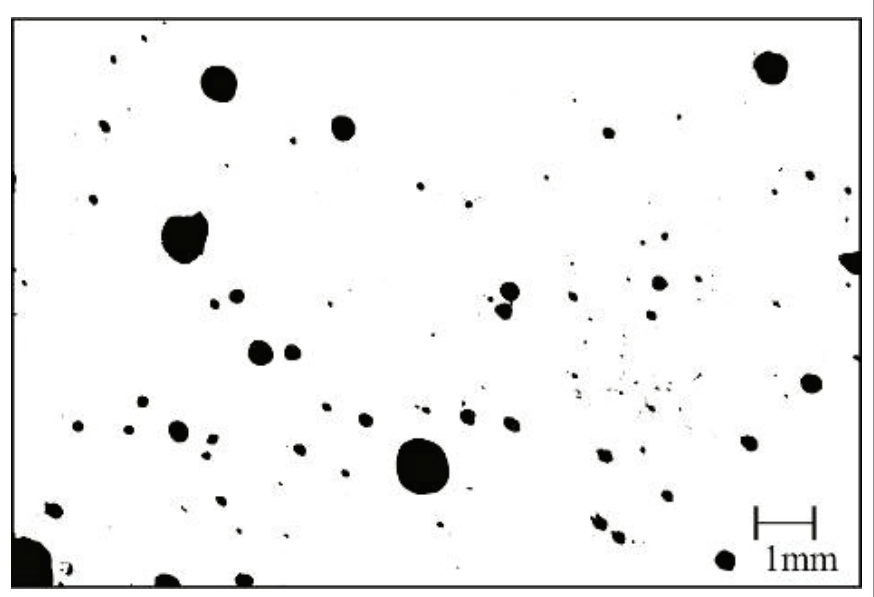

D 
OHK1/2T/11), and the Erasmus Mundus External Cooperation Window EMEWC - EUBrazil Startup is gratefully acknowledged.

\section{References}

[01] Taylor, H. Cement Chemistry. Academic Press, New York, 1990.

[02] Jennings $\mathrm{H}$. A model for the microstructure of calcium silicate hydrate in cement paste, Cement and Concrete Research, 30; 6; 2000; 101-116.

[03] Němeček J. Nanoindentation of Heterogeneous Structural Materials, Habilitation Thesis, CTU Reports, ČVUT Praha; 2010.

[04] Němeček J, Šmilauer V, Kopecky L. Nanoindentation characteristics of alkali-activated aluminosilicate materials, Cement and Concrete Composites 33; 2; 2010; 163-170.

[05] Constantinides G, Ulm F-J. The effect of two types of C-S-H on the elasticity of cement-based materials: Results from nanoindentation and micromechanical modeling, Cement and Concrete Research; 34; 1 ; 2004; 67-80.

[06] Calabri L, Pugno N, Valeri S. AFM Nanoindentation Method: Geometrical Effects of the Indenter Tip, Nanoscience and Technology - Applied Scanning Probe Methods XI; 2009; 139-164.

[07] Scrivener K L. Backscattered electron imaging of cementitious microstructures: understanding and quantification, Cement and Concrete Composites; 26; 8; 2004; 935-945

[08] Chen J J, Sorelli L, Vandamme M, Ulm F-J. Chanvillard G. A Coupled Nanoindentation/SEM-EDS Study on Low Water/Cement Ratio Portland Cement Paste: Evidence for $\mathrm{C}-\mathrm{S}-\mathrm{H} / \mathrm{Ca}(\mathrm{OH})_{2}$ Nanocomposites, Journal of the American Ceramic Society; 93; 5; 2010; 1484-1493.

[09] Fischer-Cripps A C. Nanoindentation. Springer, 2002

[10] Oliver W C, Pharr G M. An improved technique for determining hardness and elastic modulus using load and displacement sensing indentation experiments, Journal of Materials Research; 7; 1992; 1564-1583.

[11] Vandamme M, Ulm F-J. Viscoelastic solutions for conical indentation, International Journal of solids and structures; 43; 10; 2006; 3142-3165.

[12] Zaoui A. Continuum Micromechanics: Survey, Journal of Engineering Mechanics 128 (8) (2002) 808-816.

[13] Eshelby J. The determination of the elastic field of an ellipsoidal inclusion and related problems, in: Proc Royal Society of London A; 1957; 376-396.

[14] Zeman J, Vondřejc J, Novák J, Marek I. "Accelerating a FFT-based solver for numerical homogenization of periodic media by conjugate gradients", Journal of Computational Physics; 229; 21; 2010; 8065-8071.

[15] Garboczi E J. Finite Element and Finite Difference Programs for Computing the Linear Electric and Elastic Properties of Digital Images of Random Materials, Tech. rep., NIST Building and Fire Research Laboratory, Gaithersburg, Maryland; 1998.

[16] Moulinec H, Suquet P, A fast numerical method for computing the linear and nonlinear mechanical properties of composites, Computer Methods in Applied Mechanics and Engineering; 157; 1-2; 1998; 69-94.

[17] Sorelli L, Constantinides G, Ulm F-J, Toutlemonde F. The nano-mechanical signature of Ultra High Performance Concrete by statistical nanoindentation techniques, Cement and Concrete Research; 38; 2008; 1447-1456.

[18] Bharatkumar B H, Narayanan R, Raghuprasad B K, Ramachandramurthy D S, Mix proportioning of high performance concrete, Cement and Concrete Composites, 23, 1, 2001, 71-80.

[19] Constantinides G, Chandran K R, Ulm F-J, Vliet K V. Grid indentation analysis of composite microstructure and mechanics: Principles and validation, Materials Science and Engineering A; 430; 2006; 189-202.

[20] Mori T, Tanaka K. Average stress in matrix and average elastic energy of materials with misfitting inclusions, Acta Metallurgica; 21; 5; 1973; 1605-1609.

[21] Silva, W R L, Damo, G, Oliveira, A L, Tochetto, $E$, Prudêncio JR, L R. Influence of Air Temperature on the Performance of Different Water Reducing Admixtures with Respect to the Properties of Fresh and Hardened Mortar. In: Advances in Civil Engineering, 2010, Article ID 136768.

[22] ASTM E1876-01, Standard Test Method for Dynamic Young's Modulus, Shear Modulus, and Poisson's Ratio by Impulse Excitation of Vibration, Annual Book of ASTM Standards, American Society for Testing and Materials, 2006.

[23] Miller M, Bobko C, Vandamme M, Ulm F-J, "Surface roughness criteria for cement paste nanoindentation", Cement and Concrete Research; 38; 4; 2008; 467-476.

[24] Němeček J, Lukeš J. On the Evaluation of Elastic Properties from Nanoindentation of Heterogeneous Systems. Chemicke Listy; 2010; 104; 279-282.

[25] Němeček J. Creep effects in nanoindentation of hydrated phases of cement pastes, Materials Characterization; 60; 9; 2009; 1028-1034.

[26] Nochaiya T, Wongkeo W, Chaipanich A. Utilization of fly ash with silica fume and properties of Portland cement-fly ash-silica fume concrete, Fuel 89; 3; 2010; 768-774

[27] Ravina D, Mehta P K. Properties of fresh concrete containing large amounts of fly ash, Cement and Concrete Research; 16; 2; 1986; 227-238.

[28] Montgomery D C, Runger G C. Applied Statistics and Probability for Engineers, 4th Edition; 2007.

[29] Velez K, Maximilien S, Damidot D, Fantozzi G, Sorrentino F. Determination by nanoindentation of elastic modulus and hardness of purê constituents of Portland cement clinker, Cement and Concrete Research; 31; 2001; 555-561.

[30] Fukuhara M, Sanpei A, Shibuki K. Low Temperature Elastic Moduli, Debye Temperature and Internal Dilational and Shear Frictions of Fused Quartz, Journal of Materials Science; 32; 1997; 1207-1211. 